\title{
Investing in the health of girls and women: a best buy for sustainable development
}

\author{
Human rights, theory, evidence, and common sense all suggest that greater investment in women's \\ health could be among the "best buys" for broader economic development and societal wellbeing, \\ say Michelle Remme and colleagues
}

I nvestments in health are known to generate large social and economic benefits, in addition to saving lives and improving quality of life. ${ }^{1}$ Yet given the 2030 global development agenda and its broad set of priorities, resources need to be targeted to interventions with the greatest impacts. The disproportionate impact on economic development of investments in women's education and economic participation is well known, but it is less well understood that programmes that improve women's health could have substantial and disproportionately higher economic and social returns, compared with other uses of social resources. $^{23}$

Meeting women's health needs and eliminating gender inequality are moral imperatives and fundamental human rights, and investment in women's health

\section{KEY MESSAGES}

- Investing in women's health could redress violations in women's rights and gender inequities, as well as generating disproportionately large health, economic, social, and environmental gains

- Healthy women and girls tend to be more productive in both paid and unpaid work, have higher returns on educational investments, and contribute to positive intergenerational and community spillover effects and favourable demographics

- Better women's health can be a result of progress towards universal health coverage and a contributing factor

- Health systems often fail women because of fundamental biases in medicine and in the design of healthcare delivery and financing models

- Investments in women's health can and should be used for more gender transformative and multisectoral approaches to maximise benefits beyond health should therefore not require justification. However, the case is also compelling beyond the immediate health benefits. ${ }^{45}$ Although women live longer than men, they have specific unmet health needs and higher morbidity. ${ }^{6}$ In addition, women's biological and social roles make them central to intergenerational transfers and demographic and development effects. Moreover, women not only provide most of the informal care in homes and communities, they also represent $70 \%$ of the global health workforce, making them central to overall population health. ${ }^{7}$ By considering only the direct health benefits of investments in women's health, we risk undervaluing the broader societal benefits and underinvesting in programmes to improve it.

We summarise the latest evidence on the impact of investing in women's and girls' health for the health, wealth, cohesiveness, and wellbeing of society in low, middle, and high income countries. We include evidence on sources of benefit embedded in a sustainable development framework $^{8}$ that considers the standalone and interconnected goals of gender equality, ${ }^{9}$ human development, economic development, universal health coverage, political stability, and environmental sustainability.

Gender equality and women's empowerment Women's access to healthcare and their ability to achieve good health are measures of gender equality and the realisation of women's human rights. This entails social norms that value women and girls' health; availability of quality healthcare options; and autonomy and informed choice for women and girls, free of coercion, discrimination, and violence.

Yet, in certain settings-for example, in India and Ethiopia-healthcare seeking and immunisation coverage are lower for girls, irrespective of socioeconomic factors, owing to son preference. ${ }^{10} 11$ Moreover, women receive less evidence based clinical care than men, because the male body remains the reference in medicine and biomedical research, with significantly fewer women in clinical trials and fewer females in animal studies. ${ }^{12}$ This gender bias limits the realisation of women's right to health and is evidenced by more side effects from treatment, fewer accurate diagnoses, and less treatment that is evidence based or adherent to guidelines. ${ }^{13-15}$ For example, women in the United States and the United Kingdom are $25 \%$ and 50\% more likely than men to be misdiagnosed for a stroke or heart attack, respectively. ${ }^{16}$

Investing in women's health can improve both health outcomes and gender equality (box 1). The literature has tended to investigate the enabling role of women's empowerment for health service uptake and health outcomes. ${ }^{17}$ Evidence suggests a strong association between women's use of family planning and their empowerment and agency, although the direction of effect is unclear. Yet, evidence also suggests that rights based, gender responsive health interventions and health systems can promote gender equity and women's rights. ${ }^{18}$ For example, overcoming bias in medical research and clinical practice can increase the efficiency and equity of healthcare. This has been found in the US, where cardiovascular mortality among women has declined dramatically in the past decade, partly as a result of a greater focus on women's specific unmet needs and better adherence to treatment guidelines. ${ }^{19}$ While many women experience mistreatment and abuse during facility based childbirth (including physical abuse; non-consented, non-confidential, or undignified care; discrimination; abandonment; and detention), respectful maternity care policies could reduce these violations in women's rights and improve quality of care, and service uptake. ${ }^{20}$

Ensuring that women are healthier also requires approaches to reduce sexual and physical violence, which one in three women experience in their lifetime. ${ }^{21}$ Evidence suggests that effective 
Box 1: Gender equality and equity

- Gender equality means "the absence of discrimination on the basis of a person's sex in opportunities, allocation of resources or benefits, and access to services." "

- Gender equity means "fairness and justice in the distribution of benefits, power, resources, and responsibilities between women and men. The concept recognises that women and men have different needs, power, and access to resources and that these differences should be identified and addressed in a manner that rectifies the imbalance between the sexes" (World Health Organization, 2002). ${ }^{9}$

- Gender equality in opportunities and rights is therefore used when referring to it as a goal or end outcome, while gender equity is used when referring to the fair distribution of, and access to, healthcare inputs as a means of achieving the goal.

investments to prevent violence against women combine interventions that tackle women's health needs, support their economic empowerment, and challenge inequitable gender norms and power dynamics in society. ${ }^{21}$ Such transformative approaches involving women and men have reduced the incidence of intimate partner violence by up to $50 \%$ and transformed gender norms within one to two years of intervention in a range of settings (including South Africa, Rwanda, Uganda, Tajikistan, Nepal, and Afghanistan). ${ }^{22}$

\section{Human and economic development}

The ethical arguments and justifications for investing in the overall and reproductive health of women and girls are magnified by theory and evidence highlighting the value of health as a form of human capital that promotes economic wellbeing at the individual, familial, and societal levels. ${ }^{23}$ Human capital promotes income growth and poverty alleviation through five main pathways: labour; education; capital accumulation; intergenerational, familial, and community spillovers; and favourable demographics. While most of these pathways apply to men and boys as well, we focus on how healthier women and girls affect economic growth and development and where there is a differential impact.

\section{Labour}

Healthy women tend to be more productive in the paid workforce and in their unpaid work, which includes contributions to fam- ily economic activities and a disproportionate share of child rearing, care for elderly or sick family members, and domestic work..$^{24}$ Globally, $76 \%$ of the 16.4 billion hours a day of unpaid care work is done by women. ${ }^{25}$ Although not equally valued in standard economic metrics, both paid and unpaid work are clearly vital to household and societal welfare. ${ }^{26}$

Healthy women also tend to miss fewer workdays owing to illness and be more productive when they work (provided the total hours worked do not exceed healthy levels). For example, multi-micronutrient supplementation among female tea pickers in India increased their productivity by $12 \% .{ }^{27}$ In the US, modelling suggests that reduced maternal mortality between 1920 and 1970 resulted in a 52\% increase in labour force participation among women of reproductive age. ${ }^{27}$ of course, these effects of health on economic wellbeing are mediated by legal, institutional, and cultural factors that influence women's economic freedom, access to and control over property, employment, pay, capital, and household decisions. ${ }^{28}$

\section{Education}

The health of women and girls in utero, infancy, childhood, and adolescence is reflected in their records of school attendance, progression through the education system, cognitive function, and their experience of long term physical and mental impairments associated with illness and injury. ${ }^{29}$ Studies from Pakistan and Guatemala found that improved nutritional status among girls significantly increased their schooling (with less or no effect for boys). ${ }^{27}$ The improved health of women and girls thus increases the returns on educational investment and is linked to their lifetime earnings, mainly via stronger representation in the paid workforce, greater economic empowerment, increased productivity, and greater longevity. ${ }^{27}$

\section{Intergenerational, familial, and community} spillover effects

Healthy women also promote economic wellbeing and progress by strengthening the environment-materially, emotionally, and socially-in which children are raised, in their nuclear and extended families and communities. Studies show that maternal health at birth, in childhood, and during pregnancy directly influences the health of children at birth, during their childhood, and into adulthood, with better maternal health reducing stunting and improving cognitive development and later productivity. ${ }^{27}$ For example, studies from China and Nigeria found that fetal exposure to acute maternal malnutrition had negative impacts on risks of hypertension, literacy, and income in adulthood. ${ }^{27}$

In Romania, children born after the abortion ban in 1967 had worse educational and labour market achievements. ${ }^{27}$ In addition to affecting the health of her children, a mother's health is linked to her spouse's status in the labour market and earnings. ${ }^{30}$ Moreover, the larger the share of household income generated by women, the larger the share of spending on nutrition and the smaller that spent on tobacco and alcohol. ${ }^{31}$

\section{Favourable demographics}

Higher rates of infant and child survival more than offset reductions in fertility, allowing families and countries to escape from the heavy burden of youth dependency and enjoy the prospect of a demographic dividend. ${ }^{32}$ For example, economic modelling suggests that Kenya, Nigeria, and Senegal could increase national income per person by 31-65\% if their unmet need for family planning was met. ${ }^{27}$ In Bangladesh, a drop in fertility rates was associated with increased earnings and assets for women. ${ }^{27}$ Indeed, in settings with low economic growth and high fertility, improved health in women tends to accelerate fertility decline and concomitant economic gains. Improved male health, however, often results in higher fertility and therefore delayed demographic transition and economic take-off to sustained growth. ${ }^{2833} 34$

\section{Environmental sustainability}

Better reproductive health could have important implications for the environment through reduced population growth and mitigation of natural resource degradation. ${ }^{35-37}$ Indeed, countries responding to the effects of climate change have emphasised how rapid population growth is exacerbating the impact of climate change on their communities, pointing to the need to prioritise access to voluntary family planning. ${ }^{38}$ While the literature on how climate change affects women's and girls' health is growing, less empirical evidence is available on the impact of women's access to, and uptake of, family planning services on climate change and adaptation mechanisms. ${ }^{437}$ Interestingly, several studies identify opportunities to tackle health, family planning, and environment in an integrated manner to maximise their combined effect. ${ }^{37} 39$ 


\section{Universal health coverage and financial protection}

Universal health coverage means that everyone has access to essential health services that are of sufficient quality to be effective and which do not result in financial hardship for the individual or their household. ${ }^{4041}$ As countries progress towards universal health coverage, prioritising health services that predominantly affect women, including essential sexual and reproductive health services, will be key to achieving financial protection for the most vulnerable. ${ }^{42-46}$ Studies show that maternal complications, emergency obstetric care, maternal mortality, and female cancers often result in catastrophic health spending in low and middle income countries, especially among poorer households. ${ }^{47} 48$ There is also greater income related inequity in access to women's health services, compared with access to child health services. ${ }^{424649}$

Moreover, the need for out-of-pocket payments has been found to constrain women's use of healthcare services, more than that of men, given women's limited access to and control over household financial resources. ${ }^{43}$ While spending on sexual and reproductive health services in low and middle income countries is particularly regressive, with the poorest households spending up to 10 times more of their income than wealthier households, ${ }^{50}$ similar trends are found for the growing burden of non-communicable diseases, where vulnerable households spend between $5 \%$ and $50 \%$ of their monthly income covering the costs of chronic illnesses. ${ }^{51}$ Although out-of-pocket spending is the most inequitable form of health financing, it does imply some access to health services, whereas women are more likely to forgo healthcare altogether for financial reasons or to access poorer quality healthcare. ${ }^{52}$ Older women are less likely to have been formally employed and built up a safety net or pension but also live longer than men, exposing them to a higher risk of catastrophic health expenditures. ${ }^{24}$ While we know more about the long term social, health, and economic consequences of maternal mortality for surviving infants, limited evidence is available on the social and economic burden of cancers in women and other deaths not related to child bearing. ${ }^{47}$

Because more than $35 \%$ of health expenditure is paid out of pocket as user fees, and 100 million people are pushed into poverty each year after catastrophic health expenditures, ${ }^{53}$ removing user fees and ensuring equitable healthcare financing-a key tenet of universal health coverage -is one mechanism for reducing this burden. Another is reducing women's need for healthcare by improving their health and wellbeing across their life course. Investing in women's health services and promotion could lead to a cycle that improves women's health outcomes and in turn reduces the economic burden of utilising health services. For example, access to sexual and reproductive health services, better mental health, and fewer chronic conditions increase women's employment and thereby their ability to contribute to tax and income based universal health coverage schemes. ${ }^{54}$

Better women's health can be both a result of progress towards universal health coverage and a contributing factor, given that 165 million female healthcare providers form the backbone of health systems worldwide, delivering health services to five billion people and generating $\$ 3 \mathrm{tn}(€ 2.3 \mathrm{tn}$; €2.7tn) in global health. ${ }^{4}$ Even more women provide informal health and social care in households and the community. ${ }^{55}$ The health of healthcare professionals and caregivers is decisive for access to quality health services by those who need them. In addition, ensuring that women can perform their duties free from violence and harassment in the workplace is critical to uphold their rights, as well as sustaining universal health coverage, which increasingly relies on frontline workers. Nurses, for example, are three times more likely to experience violence compared with other professional groups and thus are more likely to leave their jobs. ${ }^{55}$

\section{Political participation and stability}

Healthy, educated, income generating, and empowered women are likely to assume more prominent and active roles in a community and to show less tolerance for gender inequality, lack of transparency, and lack of responsive political leadership. ${ }^{2}$ While societies in which women are more politically active would conceivably be more stable politically, evidence for this is limited. Women's health issues play a key part in voter preferences, and associations have been found between women's health status (reduced mortality) and political participation, but it is primarily thought that better political participation leads to investments and improvements in women's health, rather than vice versa. ${ }^{456}$ One modelling study found that US health aid (partly focused on women's health) had positive effects on state stability in subSaharan Africa. ${ }^{57}$

\section{Conclusions}

Investing in women's health could redress violations in women's rights and gender inequities, as well as generating disproportionately large health, economic, social, and environmental gains. Given the ambitious 2030 sustainable development goal agenda and its \$3.9tn annual price tag, identifying and prioritising "accelerators" that have multiple impacts across development targets is vital to achieve these goals. ${ }^{58}$ Women's health programmes could be particularly critical entry points for integrated programming across sectors and development objectives, such as combining sexual and reproductive health services with interventions that challenge gender inequitable norms or support climate change mitigation. Indeed, investments in women's health should be used for more gender transformative and multisectoral approaches to maximise benefits beyond health.

Nonetheless, several key gaps exist in the evidence base. Firstly, considerably more literature examines how non-health factors and other development outcomes influence women's health than the bi-directionality of this relation and how improvements in women's health affect broader sustainable development, including universal health coverage, political participation, and environmental sustainability. Moreover, few studies have considered the impact of women's health beyond reproductive health and across the life course. ${ }^{459}$ The evidence around universal health coverage provides a limited understanding of the differential gendered effects of different financing mechanisms or differences in out-of-pocket expenditures, catastrophic expenditures, and economic household burden from a woman's or man's ill health. ${ }^{43}$

With the expected development gains from investments in women's health, elements of healthcare systems need to be re-engineered to respond better to the needs of women. Despite calls for patient centred healthcare, health systems often fail women because of fundamental biases in medicine and in the design of healthcare delivery and financing models. For example, women are three times more likely to die from a serious heart attack owing to unequal treatment. ${ }^{15}$ Furthermore, health financing schemes based on formal employment and civil service were established in Europe in 
the 19th century to keep men healthy for battle and work in rapidly industrialising economies, yet they are still actively promoted across the world despite large informal work sectors being dominated by women. ${ }^{43}$ Additionally, the most vulnerable women typically receive healthcare from the most under-resourced, undertrained, and undervalued health workers in the health system (community health workers, traditional birth attendants, and relatives). ${ }^{4}$

Moreover, while many countries have developed primary healthcare systems around maternal and child health, we need to recognise that women's health is more than maternal and reproductive health ${ }^{4}$ and that its impact on development extends beyond their reproductive role. For example, as primary caregivers and healthcare providers, women are in a key position to alter non-communicable disease risk factors at home and are central in responding to non-communicable diseases across the world, especially in resource limited settings where health systems cannot absorb and respond to the growing needs of chronic conditions.

The global landscape and political climate are areas of disinvestment in women's health, and women's sexual and reproductive health and rights in particular. ${ }^{60}$ Health for all at all ages is a fundamental human right and the ambition of the sustainable development goals for health. ${ }^{61}$ Recent evidence and thinking on the value to society of good health justify greater investment in health overall, in addition to increasing the amount spent on women and girls. ${ }^{133}$ In the context of constrained healthcare resources and limited development budgets, we need to prioritise health interventions that maximise health gains, increase health equity, and optimise other development goals. Human rights, theory, evidence, and common sense all suggest that greater investment in women's health could be among the "best buys" for broader economic development and societal wellbeing.

We thank Professor TK Sundari Ravindran and peer reviewers for their comments on earlier drafts.

Competing interests: We have read and understood BMJ policy on declaration of interests and have no interests to declare. DEB's work on this paper was supported by the Norwegian Agency for Development Cooperation under grant number QZA-0408-

QZA-12/0628 and by the National Institute on Ageing, National Institutes of Health, under award number P30AG024409.

Provenance and peer review: Commissioned; externally peer reviewed.

This article is part of a series commissioned by The $B M J$.
Michelle Remme, research lead ${ }^{1}$

Anna Vassall, professor ${ }^{2}$

Gabriela Fernando, PhD fellow ${ }^{1}$

David E Bloom, professor ${ }^{3}$

${ }^{1}$ United Nations University International Institute for Global Health, Kuala Lumpur, Malaysia

${ }^{2}$ London School of Hygiene and Tropical Medicine, London, UK

${ }^{3}$ Harvard TH Chan School of Public Health, Harvard University, Boston, USA

Correspondence to: M Remme michelle.remme@unu.edu

\section{(2) $(1)$}

This is an Open Access article distributed in accordance with the Creative Commons Attribution Non Commercial (CC BY-NC 4.0) license, which permits others to distribute, remix, adapt, build upon this work non-commercially, and license their derivative works on different terms, provided the original work is properly cited and the use is non-commercial. See: http://creativecommons.org/ licenses/by-nc/4.0/.

\section{Check for updates}

1 Jamison DT, Summers LH, Alleyne G, et al. [Global health 2035: a world converging within a generation]. Salud Publica De Mexico 2015;57:44467. doi:10.21149/spm.v57i5.7625

2 Duflo E. Women empowerment and economic development. Journal of Economic Literature 2012;50 (4):1051-79. doi:10.1257/ jel.50.4.1051

3 Dabla-Norris E, Kochhar K. Closing the gender gap. Finance Development 2019;56:1

4 Langer A, Meleis A, Knaul FM, et al. Women and Health: the key for sustainable development. Lancet 2015;386:1165-210. doi:10.1016/S01406736(15)60497-4

5 Stenberg K, Axelson H, Sheehan P, et al, Study Group for the Global Investment Framework for Women's Children's Health. Advancing social and economic development by investing in women's and children's health: a new Global Investment Framework. Lancet 2014;383:1333-54. doi:10.1016/S01406736(13)62231-X

6 Crimmins EM, Shim H, Zhang YS, Kim JK. Differences between men and women in mortality and the health dimensions of the morbidity process. Clin Chem 2019;65:135-45. doi:10.1373/ clinchem.2018.288332

7 World Health Organization. Delivered by women, led by men: a gender and equity analysis of the global health and social workforce. 2019. https://apps.who.int/iris/bitstream/hand le/10665/311322/9789241515467-eng. pdf?ua=1.

8 Waage J, Yap C, Bell S, et al. Governing the UN sustainable development goals: interactions, infrastructures, and institutions. Lancet Glob Health 2015;3:e251-2. doi:10.1016/S2214109X(15)70112-9

9 World Health Organization. Mainstreaming gender equity in health: the need to move forward-Madrid statement. Copenhagen: WHO Regional Office for Europe, 2002. http://www.euro.who.int/_data/ assets/pdf_file/0008/76508/A75328.pdf.

10 Corsi DJ, Bassani DG, Kumar R, et al. Gender inequity and age-appropriate immunization coverage in India from 1992 to 2006. BMC Int Health Hum Rights 2009;9(suppl 1):S3. doi:10.1186/1472698X-9-S1-S3

11 Weber AM, Cislaghi B, Meausoone V, et al, Gender equality, norms and Health Steering Committee.
Gender norms and health: insights from global survey data. Lancet 2019;393:2455-68. doi:10.1016/S0140-6736(19)30765-2

12 Putting gender on the agenda. Nature 2010;465(7299):665

13 Watson S, Caster O, Rochon PA, den Ruijter H. Reported adverse drug reactions in women and men: aggregated evidence from globally collected individual case reports during half a century. EClinicalMedicine 2019;17:100188. doi:10.1016/j. eclinm.2019.10.001

14 Ramirez FD, Motazedian P, Jung RG, et al. Sex bias is increasingly prevalent in preclinical cardiovascular research: implications for translational medicine and health equity for women. A systematic assessment of leading cardiovascular journals over a 10-year period. Circulation 2017;135:625-6. doi:10.1161/ CIRCULATIONAHA.116.026668

15 Alabas OA, Gale CP, Hall M, et al. Sex differences in treatments, relative survival, and excess mortality following acute myocardial infarction: national cohort study using the SWEDEHEART registry. J Am Heart Assoc 2017;6:e007123. doi:10.1161/ JAHA.117.007123

16 Newman-Toker DE, Moy E, Valente E, Coffey $R$, Hines AL. Missed diagnosis of stroke in the emergency department: a cross-sectional analysis of a large population-based sample. Diagnosis (Berl) 2014;1:155-66. doi:10.1515/dx-2013-0038

17 Taukobong HFG, Kincaid MM, Levy JK, et al. Does addressing gender inequalities and empowering women and girls improve health and development programme outcomes? Health Policy and Planning 2016;31:1492-514. doi:10.1093/heapol/czw074

18 Heymann J, Levy JK, Bose B, et al, Gender Equality, Norms and Health Steering Committee. Improving health with programmatic, legal, and policy approaches to reduce gender inequality and change restrictive gender norms. Lancet 2019;393:252234. doi:10.1016/S0140-6736(19)30656-7

19 Mehta LS, Beckie TM, DeVon HA, et al, American Heart Association Cardiovascular Disease in Women and Special Populations Committee of the Council on Clinical Cardiology, Council on Epidemiology and Prevention, Council on Cardiovascular and Stroke Nursing, and Council on Quality of Care and Outcomes Research. Acute Myocardial Infarction in Women: A Scientific Statement From the American Heart Association. Circulation 2016;133:916-47. doi:10.1161/CIR.0000000000000351

20 Downe S, Lawrie TA, Finlayson K, Oladapo OT. Effectiveness of respectful care policies for women using routine intrapartum services: a systematic review. Reproductive Health 2018;15(1):23. doi:10.1186/s12978-018-0466-y

21 Michau L, Horn J, Bank A, Dutt M, Zimmerman C. Prevention of violence against women and girls: lessons from practice. Lancet 2015;385:1672-84. doi:10.1016/S0140-6736(14)61797-9

22 Gibbs A, Bishop K. Preventing violence against women and girls: combined economic empowermen and gender-transformative interventions. Evidence review. 2019. https://www.whatworks.co.za/ documents/publications/354-eco-and-genderweb/ file.

23 Bloom DE, Canning D. The health and wealth of nations. Science 2000;287:1207-1209. doi:10.1126/science.287.5456.1207

24 International Labour Office. World employment and social outlook: trends for women 2018-Global snapshot. IRL, 2018.

25 International Labour Office. Care work and care jobs for the future of decent work. ILO, 2018.

26 Waring M. Counting for something! Recognising women's contribution to the global economy through alternative accounting systems. Gender and Development 2003;11(1):35-43. doi:10.1080/741954251

27 Onarheim KH, Iversen JH, Bloom DE. Economic benefits of investing in women's health: a 
systematic review. PLoS One 2016:11:e0150120. doi:10.1371/journal.pone.0150120

28 Bloom DE, Kuhn M, Prettner K. The contribution of female health to economic development. Econ J (Lond) (forthcoming).

29 Almond D, Currie J. Killing me softly: the fetal origins hypothesis. Journal of Economic Perspectives 2011;25:153-72. doi:10.1257/jep.25.3.153

30 Bhalotra S, Rawlings SB. Intergenerational persistence in health in developing countries: the penalty of gender inequality?Journal of Public Economics 2011;95:286-99. doi:10.1016/j. jpubeco.2010.10.016

31 Hoddinott J, Haddad L. Does female income share influence household expenditures? Evidence from Cote d'Ivoire. Oxford Bulletin of Economics and Statistics 1995:57:77-96. doi:10.1111/j.1468-0084.1995.tb00028.x

32 Lloyd CB, Ivanov S. The effects of improved child survival on family planning practice and fertility. Stud Fam Plann 1988;19:141-61. doi:10.2307/1966750

33 Bloom DE, Kuhn M, Prettner K. Invest in women and prosper. Finance Dev 2017:54:50-5. https://www.imf. org/external/pubs/ft/fandd/2017/09/bloom.htm

34 Diebolt C, Perrin F. From stagnation to sustained growth: the role of female empowerment. American Economic Review 2013;103:545-9. doi:10.1257/ aer.103.3.545

35 Dasgupta PS, Ehrlich PR. Pervasive externalities at the population, consumption, and environment nexus. Science 2013;340:324-8. doi:10.1126/ science.1224664

36 Cleland J, Bernstein S, Ezeh A, Faundes A, Glasier A, Innis J. Family planning: the unfinished agenda. Lancet 2006;368:1810-27. doi:10.1016/S01406736(06)69480-4

37 Stephenson J, Newman K, Mayhew S. Population dynamics and climate change: what are the links?] Public Health (Oxf) 2010;32:150-6. doi:10.1093/ pubmed/fdq038

38 Bryant L, Carver L, Butler CD, Anage A. Climate change and family planning: least-developed countries define the agenda. Bull World Health Organ 2009;87:852-7. doi:10.2471/BLT.08.062562

39 Mohan V, Shellard T. Providing family planning services to remote communities in areas of high biodiversity through a population-healthenvironment programme in Madagascar. Reprod Health Matters 2014;22:93-103. doi:10.1016/ S0968-8080(14)43766-2
40 Bloom DE, Khoury A, Subbaraman R. The promise and peril of universal health care. Science 2018;361:6404. doi:10.1126/science.aat9644

41 World Health Organization. Health systems financing: the path to universal coverage. WHO, 2010.

42 Victora CG, Barros AJ, Axelson H, et al. How changes in coverage affect equity in maternal and child health interventions in 35 Countdown to 2015 countries: an analysis of national surveys. Lancet 2012:380:114956. doi:10.1016/S0140-6736(12)61427-5

43 Witter S, Govender V, Ravindran TKS, Yates R. Minding the gaps: health financing, universal health coverage and gender. Health Policy and Planning 2017;32(suppl_5):v4-12.doi:10.1093/ heapol/czx063

44 Tangcharoensathien V, Chaturachinda K, Im-em W. Commentary: Thailand: sexual and reproductive health before and after universal health coverage in 2002. Global Public Health 2015;10:246-8. doi:10. 1080/17441692.2014.986166

45 Starrs AM, Ezeh AC, Barker G, et al, et al. Accelerate progress-sexual and reproductive health and rights for all: report of the Guttmacher-Lancet Commission. Lancet 2018;391:2642-92. doi:10.1016/S01406736(18)30293-9

46 Quick J, Jay J, Langer A. Improving women's health through universal health coverage. PLoS Med 2014;11(1):e1001580. doi:10.1371/journal. pmed.1001580

47 Ginsburg O, Bray F, Coleman MP, et al. The global burden of women's cancers: a grand challenge in global health. Lancet 2017;389:847-60. doi:10.1016/S0140-6736(16)31392-7

48 Kes A, Ogwang S, Pande R, et al. The economic burden of maternal mortality on households: evidence from three sub-counties in rural western Kenya. Reproductive Health 2015;12(suppl 1):S3. doi:10.1186/1742-4755-12-S1-S3

49 Barros AJD, Ronsmans C, Axelson H, et al. Equity in maternal, newborn, and child health interventions in Countdown to 2015: a retrospective review of survey data from 54 countries. Lancet 2012;379:1225-33. doi:10.1016/S0140-6736(12)60113-5

50 Haghparast-Bidgoli H, Pulkki-Brännström AM, Lafort Y, et al. Inequity in costs of seeking sexual and reproductive health services in India and Kenya. International Journal for Equity in Health 2015;14:84. doi:10.1186/s12939-015-0216-5

51 Kankeu HT, Saksena P, Xu K, Evans DB. The financial burden from non-communicable diseases in lowand middle-income countries: a literature review.
Health Research and Policy Systems 2013;11:31. doi:10.1186/1478-4505-11-31

52 Janssens W, Goedecke J, de Bree GJ, Aderibigbe SA, Akande TM, Mesnard A. The financial burden of non-communicable chronic diseases in rural Nigeria: wealth and gender heterogeneity in health care utilization and health expenditures. PLoS One 2016;11:e0166121. doi:10.1371/journal. pone.0166121

53 Xu K, Soucat A, Kutzin J. Public spending on health: a closer look at global trends. 2018. https://apps.who. int/iris/bitstream/handle/10665/276728/WHOHIS-HGF-HF-WorkingPaper-18.3-eng.pdf?ua=1

54 Pit SW, Byles J. The association of health and employment in mature women: a longitudinal study. Journal of Women's Health 2012;21:273-80. doi:10.1089/jwh.2011.2872

55 Sen G, Govender V, El-Gamal S. Universal health coverage, gender equality and social protection: a health systems approach. 2018, http://www. unwomen.org/-/media/headquarters/attachments/ sections/csw/63/egm/sen\%20gbackground $\% 20$ paperdraftegmspsbp2.pdf?la=en\&vs=4355

56 Kawachi I, Kennedy BP, Gupta V, Prothrow-Stith D. Women's status and the health of women and men: a view from the States. Soc Sci Med 1999;48:21-32. doi:10.1016/S0277-9536(98)00286-X

57 Gupta V, Mason-Sharma A, Lyon ZM, Orav EJ, Jha AK, Kerry VB. Has development assistance for health facilitated the rise of more peaceful societies in subSaharan Africa?Global Public Health 2018;13:1796806. doi:10.1080/17441692.2018.1449232

58 Nilsson M, Griggs D, Visbeck M. Policy: Map the interactions between sustainable development goals. Nature 2016;534:320-2. doi:10.1038/534320a

59 Kuruvilla S, Sadana R, Montesinos EV, et al. A life-course approach to health: synergy with sustainable development goals. Bull World Health Organ 2018;96:42-50. doi:10.2471/ BLT.17.198358

60 The Lancet. The erosion of women's sexual and reproductive rights. Lancet 2019;393:1773. doi:10.1016/S0140-6736(19)30990-0

61 Manandhar M, Hawkes S, Buse K, Nosrati E, Magar V. Gender, health and the 2030 agenda for sustainable development. Bull World Health Organ 2018;96:644-53. doi:10.2471/ BLT.18.21160

Cite this as: $B M J$ 2020;369:m1175

http://dx.doi.org/10.1136/bmj.m1175 